\title{
Therapeutic Mediations and Their Use in Teaching: Family Psychic Suffering
}

\section{María Antonieta Pezo del Pino*}

University of Sao Paulo, Brazil

*Corresponding Author: María Antonieta Pezo del Pino, University of Sao Paulo, Brazil.

DOI: 10.31080/ASMS.2020.04.0572
Received: February 11, 2020

Published: February 24, 2020

(C) All rights are reserved by María Antonieta Pezo del Pino.

\begin{abstract}
The transmission of psychoanalysis is a fairly broad topic, since it usually involves thinking about how psychoanalysts are formed and everything that makes up a formation. But for those of us who are dedicated to working with mental health professionals, who need tools that allow them to recognize the essence of a welcoming listening, the way in which the feeling of the other gives access to personal content, which mobilizes them, seems necessary. use some tools that go beyond a transmission of theoretical contents, concepts and their articulations with the clinic. In this proposal, we want to share the experience of using therapeutic mediators, such as dramatizing and pictography in a group Mediators that allow access to other psychic records that puts the professional in contact not only with the patient's feeling as with his or her feeling in that situation. Recognize that, in their countertransference, there are not only elements captured by an attentive listening, and yes by the effect of the presence of the other. Presence that mobilizes and captures unique, unrecognizable records with just an attentive listening when saying. Presence that imposes an intersubjective link, which needs to be deciphered in order to facilitate that the consultant not only feels heard, such as recognizing in what some sense says, presence that stimulates reflection on his saying, thinking.
\end{abstract}

Keywords: Therapeutic Mediator; Teaching; Psychic Suffering; Family

The body is interpreting, and this is very difficult in supervision, because people have words and it would be necessary that they also have their body. Rene Roussillon (2014).

\section{By way of introducing the topic}

Transmitting the experience that the clinic has for us is not an easy task. Concepts, theory of technique appear in enough when we take care professional is serving human beings in psychic suffering. In consideration, seems essential that the experience is made, from a type specific listening, looking, recognition and reflection on that what was living at the time of the meeting, encounter one who seeks help. Regardless of professional training, the theoretical line that bases the practice, the presence of the other mobilizes feelings, memories, dreams dreamed, lived, not thought, not realized, often, not elaborated. An aspect that in psychoanalysis we describe as countertransference. It can be taught that it is countertransference, but the concept will have no use whatsoever, if we do not favour that beyond knowing the concept it is essential to recognize, accept and work what the other (s) arouses in me with their presence. Countertransference is not reduced to the feelings that the patient promotes, or to the control or elimination of them. The other (s) is experienced, raises feelings of love, hate, discomfort, compassion, fear and in the best case these experiences can be instrumentalized, but, unfortunately, many of the times they are acted, without the slightest recognition, harming not only the service, as in many cases to the professional himself.

When in the space of a seminar on family assistance we need to work on the topic of psychic suffering of the families of the territory, we consider that just listing or describing what they lived daily seemed insufficient for the training experience. If the presence of 
the other, leaves a mark, mobilizes feelings, memories, we question how the simple description could give an account, be enough to express and reflect on what is lived daily. In short, how in the space of a class, not a supervision, we could connect the professional-students with their experience, their feeling. In what way, make space so that what is lived, can be used, how to transmit, about what is not possible to teacher.

Thus, in the module designed to talk about the psychic suffering of families, we divide the class into three groups: 1 ) one would make a description of situations or present a typical case; 2) another would dramatize a situation of family psychic suffering, and 3) another would show through the whole drawing, psychic suffering. The use of these therapeutic mediators also had the function of instrumentalizing the professional with resources to be used in their care.

\section{Therapeutic mediators}

Dramatizing, modelling in clay, drawing alone or together with other (s) are human activities that give pleasure to those who perform them, but we could not say that they work or are therapeutic. When activities such as stars are organised, from a frame call-are therapeutic or training is imposed that will choose and place an object mediator specific to be worked, thanks to the qualities of the object and the intended purpose. In this type of situation, it is necessary: to use the singular associations and the group associative chains, to allow the nonverbalized to find ways to be expressed, to seek that the members of the group can say, between say understand. Facilitate explore the look on themselves and on the other, feeling it and feeling that the encounter with the other me raises, listening and heard and fundamentally reflect on what other (s) occurs at the meeting, with the mediator and with the coordinator, According to Brun (2013), therapeutic mediation devices are defined by three preconditions: 1 ) approach to the materiality of a mediating object used to allow symbolization; 2) consider when possible, the verbal associations of each patient and the associative chains of groups; 3 ) the medium embodied is used as a loop joint transfers and counter transferences as sensory support links transfer-counter-transference, the interpretation of the therapist, placing stakes own sensory-motor and sensory of the language (Brun, 2013, p.95).

The mediators used: the pictogram and the dramatization of everyday life

In the psychoanalytic literature, therapeutic mediators are described as tools specific to therapeutic work in institutions, with groups and with patients with narcissistic-identity pathologies, psychosomatic, psychosis, among others. Its use is also valued with subjects who experienced traumatic situations (Pezo, 2012, 2013, 2014). In this work we want to highlight its usefulness to work in professional training, as a resource that allows the recognition of what is placed beyond thinking or conceptualizing, what arises from the sensory-motor, which in general was not represented, just lived, felt. In this paper we want to emphasize the usefulness of therapeutic mediators who would favour the passage from the sensory-motor to the symbolization, from the original process, primary to the secondary process, where the symbolization prevails, that is, to distinguish itself from the elaboration, a say between said own making. In the transmission of the clinic, listening is necessary that the attending professional can access records other than thinking about what he lived, did or said.

The group pictogram is defined as a production carried out by a couple, a group or a family, which articulates strokes, singular drawings with drawings produced associatively together with the other, thanks to intersubjective processes that simultaneously allow the intrapsychic to be intersubjective and intersubjective. group, the individual psychic reality with the shared reality. The group pictogram is a tool, a useful therapeutic mediator when a therapeutic process begins and, especially when experiencing a traumatic situation, difficult to be named. The group experience with the use of the group pictogram allows members to live, develop and subjectively appropriate experiences that could not be said. The pictogram as a symbolic writing, links the images, the sensory-perceptive, with words and senses, introduces unexpected elements that convey a meaning to each of the members and to the link encounter. This mediator makes possible, what Brun (2014) supports, that the mediator enables the passage of the sensorymotor register to the figural.

The dramatization of everyday life is another tool also useful in interventions in crisis situations and in professional training, she uses other sensory records linked to body experiences. We call the dramatization that the participants of a group put together to create a free scene, which presents some situation in everyday life. It is not proposed to work a conflict, a dream as in a psychoanalytic psychodrama session, just to reproduce, a scene lived daily, a daily journey. Obviously, the scene presented brings significant aspects, since, despite the proposal, not seeking conflict, it arises without having proposed it, in different ways. In general, the scene is built 
as a dream, based on fragments that each of the participants brings to the group and that they weave together. Like any group construction, it is presented interdiscursively, that which is unique, characteristic of each of the participants, aspects of intersubjectivity and a mesh that is characteristic of the group.

We see that the subjects when they propose this type of mediators seem as if they enter the space of the dream or play. In general, they set up a scene (dramatic or drawn) with the concern to present it, have fun, intensify what they have lived, exchange ideas, build, discuss, associate. As soon as they work together, they live intensely to feel, think and do the work that summons them as a group, what the mediator proposes and mobilizes in each of them, as intrapsychic, intersubjective and group psychic aspects.

\section{Vignette1}

In a synthetic way, I emphasize that, in two of the work groups, professionals present, with some variations, a family group consisting of a grandmother, a mother, children and grandchildren. Being the grandmother financially responsible for supporting the family and caring for the grandchildren, in one the mother of the children is alcoholic, in another it is psychotic, the children and young unemployed adults (uncles), one of them without verbal communication, just gestural (schizophrenic), the granddaughter living with the mother and uncles (a psychotic one). I will keep in one of these families, the girl (granddaughter-niece-daughter) has problems at school and in the health Institution unit when the parents are called, the grandmother appears instead of them, then at another time and Mother's scene is called. In one of the scenes, the granddaughter is close to the grandmother, looks for her lap, curls up in her and is reciprocated by the grandmother's affection. In contrast, when this same girl approaches the mother, she seeks to touch the mother's body, the hair, curl up, the mother ostensibly rejects her physically, does not receive her in his arms, on the contrary, he withdraws, moves her away from yes.

\section{Vignette2}

In the case of the group pictogram made by a small group of professionals, they perform various representations, such as portraits of people, on one side a figure appears that recalls the shout, inequality, criminality. When I ask to associate the drawing, they comment: "Scream comes in as fear of the unknown, disorientation, fear, how to do when one does not feel strong, and suffering is very strong". On the other drawings they say: "here we show the concern over time, aesthetics, being well" "financial problems" "here the family, with a daughter using marijuana, the father with financial problems, the unemployed mother, the suffering of all "" here, the child by phases of life "; "here the motherhood that brings feelings of guilt, learn to deal with it, here he wonders where I went that I was wrong"; "here we show questions of society, separation of the parents, the greatest suffering of the mother, as this leaves her strong, but suffers more". On the drawn motherhood they say: "Bring feelings of guilt, learn to deal with this, where it will be that the society is wrong, blamed or blamed, the woman the mother being or having to be stronger" [1-9].

\section{Some comments}

1. The vignettes presented show the usefulness of the mediator to recognize and elaborate what was experienced in the experience with the patients or the families they serve. A professional, who visits the families, as a Community Agent, who does not have a professional training at the time of the group talk about the experience, comments how it is difficult, sometimes, to leave a house that I visit, without feeling a huge weight overwhelmed, wishing to arrive at home and be able to cry, for what he lived with the family and could not do when he found the family. Thanks, to be able to do it in the group and share with colleagues in the classroom space, the members of the group welcome it and comment similar feelings.

2. In the other scene, where you are asked to perform a dramatization of everyday life, bring and dramatize the attention to the girl with her grandmother, then that same girl with her mother. In this dramatization, what struck us was to detect in the gesture, the body's rejection of the mother, who moves her daughter away with her hand, when she wants to caress and touch the hair, the mother responds as jaded when the girl searches. This scene is repeated by the girl, who had acted like this with the grandmother, who, contrary to the mother, welcomed her lovingly. Commenting on this scene, the colleague who dramatized the girl, says that when they thought about the scene, they had not proposed a physical approach or a body rejection, that this scene arose "without thinking about it," (as a lapse arises). At the end of the dramatization when thinking together with the group, the associations that arise is that this scene brought them the sensation experienced in the attention to the family that they presented, but, that also in many other consultations, that rejection appeared very clearly, that difficulty of connecting emotionally, as if they were very tired or with a feeling of rejection by the son taken to a consultation. 
3. We emphasize that the use of therapeutic mediators in the task of training professionals was a resource, which allowed them to connect with countertransferential aspects, unconscious records, which once placed on the scene (dramatization-pictogram) could be verbalized, shared and worked by the group of colleagues in training.

\section{Bibliography}

1. Brun A. "Therapeutic mediations and childhood psychosis". Madrid: Spain: Herder (2009).

2. Brun A. "Les mediation thérapeutiques". Le Card PSY 1.141 (2010): 24-27.

3. Brun $\mathrm{AB}$ and Chouvier R. "Roussillon, Manuel des médiations thérapeutiques". Paris: Dunod (2013).

4. Kaës R. The psychoanalytic issue of the fundamental rule and the associative process in the groups. Revue de Psychoterapie Psychanalytique de Groupe (1991): 17.

5. Kaës R. The group and the work of the preconscious in a world in crisis, International Congress of Group Psychotherapy Buenos Aires, August 29, 1995 - Publication in Spanish: Magazine of the Argentine Association of Psychology and Group Psychotherapy 3.4 (1999b).

6. Pezo, MAP Do squiggle gives therapeutic consultation to the institutional development of institutional intervention. Institute of Psychology, University of São Paulo, São Paulo (2009).

7. Pezo MAP A group association group eo Group pictogram, Institute of Psychology, University of São Paulo, São Paulo (2014).

8. Roussillon R. "To associatividade e as linguagens no verbais". Magazine of Psicanalize da Sociedade Psicanalítica de Porto Alegre 16.1 (2009): 143-165.

9. Winnicott D. "Therapeutic consultations in child psychiatry". Rio de Janeiro: Imago (1971).

\section{Assets from publication with us}

- Prompt Acknowledgement after receiving the article

- Thorough Double blinded peer review

- Rapid Publication

- Issue of Publication Certificate

- High visibility of your Published work

Website: https://www.actascientific.com/

Submit Article: https://www.actascientific.com/submission.php

Email us: editor@actascientific.com

Contact us: +919182824667 